\title{
Effect of pH on Physicochemical Properties of Cassava Starch Modification Using Ozone
}

\author{
Isti Pudjihastuti ${ }^{1}$, Noer Handayani ${ }^{2}$, and Siswo Sumardiono ${ }^{2, *}$ \\ ${ }^{1}$ Vocational Program Study of Chemical Engineering Diponegoro University, J1.Prof. Soedarto, SH, Tembalang, Semarang, Indonesia \\ 50275 \\ ${ }^{2}$ Departement of Chemical Engineering, Faculty of Engineering, Diponegoro University, J1.Prof. Soedarto, SH, Tembalang, Semarang, \\ Indonesia 50275
}

\begin{abstract}
Nowadays, starch modification is carried out in order to change the native properties into the better ones, such as high stability, brightness, and better texture. The objectives of this study are to investigate the effect of $\mathrm{pH}$ on carboxyl content, swelling power, and water solubility of starch. This research was divided into two main stages, i.e. starch modification by ozone oxidation and analysis. The physicochemical properties of modified cassava starch were investigated under various reaction $\mathrm{pH}$ of 7-10 and the reaction time between 0-240 minutes. Reaction condition at $\mathrm{pH} 10$ provided the higher value of carboxyl content and water solubility, but the lower of swelling power. This increase in solubility indicates that the modified oxidation starch readily dissolves in water, due to its small size granules and high amylose content. The significant changes of both parameters were achieved in the first 120 minutes of ozone reaction times. The graphic pattern of water solubility was in contrast with swelling power.
\end{abstract}

\section{Introduction}

Cassava is a potential material as wheat substitute due to its high level of carbohydrate. However, the baking expansion ability for bread production is low due to gluten free. Nowadays, starch modification is carried out in order to change the native properties into the better ones, such as high stability, brightness, and better texture [1]. Commonly, there are four methods of starch modification to obtain these desired characteristics, i.e. acid, enzyme, oxidation, and crossing bond modifications [1-7]. Among these, chemical and oxidation method is widely used in both food and nonfood industries.

Each modification creates the different characteristics of modified starch. Modification by chemical is provided to increase paste consistency, smoothness, clarity, and the stability in the cold storage [1-3]. Many factors influence the chemical modification, i.e. starch source, reaction condition (concentration, time, $\mathrm{pH}$, presence of catalysts), and type of chemical reagents or substituent. Acetylated starch (with low degree of substitution) is commonly obtained by the esterification using acetic anhydride in the presence of an alkaline catalyst.

Modification by oxidation reaction using hypochlorite was very popular and conducted by some researcher [8-13]. The result indicated that it could reduce viscosity and changed the structure of starch molecule, color and easier in gel formation. In the other hand, it has some drawbacks, such as the formation of residue and chloride during reaction. Oxidation using bromine reduced the enthalpy, viscosity, temperature gelatinization, and changing the structure of starch [14]. Others chemical could also use as oxidizing agent, such as chlorine, perodate, and hydrogen peroxide [15-19]. Some factors also determine the success of this modification, i.e. $\mathrm{pH}$, concentration of oxidizing agent, and temperature reaction. The reaction rate, type and amount of functional groups formed in the starch molecule depend on the $\mathrm{pH}[20,21]$.

Recently, the development of ozone application is growing rapidly due to its affordable price and also available in household scale, especially for drinking water processing [14]. Ozone is very popular in water and waste water processing. It used to reduce organic compound and micro pollutant and also inorganic compound $[15,16]$. Ozone serves to eliminate the odors, taste, color, and particle solubility in the waste water [15]. Ozone is also a strong oxidator which is able to change the structure, physicochemical, and rheological properties of starch. It also produces non residual component in modified starch process. In based on author's knowledge, there is lack of information for the use of ozone $\left(\mathrm{O}_{3}\right)$ for starch modification. The objectives of this study are to investigate the effect of $\mathrm{pH}$ on

*Corresponding author: siswo.sumardiono@che.undip.ac.id 
carboxyl content, swelling power, and water solubility of starch.

\section{Materials and Method}

\subsection{Experimental}

The research experiment was conducted in the Food Process Engineering Laboratory, Chemical Engineering Department, Diponegoro University. This research was divided into two main stages, i.e. starch modification by ozone oxidation and analysis. The equipment of this study as depicted in Figure 1.

\subsection{Ozone mass transfer in liquid phase}

First step on this study is dissolving starch in aquadest $10-40 \%$ concentration dry base and then mixed it into a stirred tank reactor. This reactor was immersed in a water bath for control temperature so that keep on desired condition (about $30-50^{\circ} \mathrm{C}$ ). This reactor was equipped with temperature and pressure sensors for identifying the temperature and pressure stability in reactor. Before through to 0.2 micron filter, Air from compressor should be flowed to flow regulator first and filtered before being through to ozoniser as ozone gas generator. Ozone gas will entered pass through under of reactor with sparger distribution. In this research, ozone rates were varied about $0-90 \mathrm{mg} \mathrm{O}_{3} / \mathrm{g}$ of starch and 7 10 of acidity range. Acidity of solution was controlled by adding $\mathrm{NaOH}$ or $\mathrm{HCl}$ solution. While the oxidizing reaction take place, sample was withdrawn every 5 minutes for measured contents of ozone in solution.

\subsection{Determination of carboxyl content}

The carboxyl content of ozone-modified cassava starch was determined by the ISO method (ISO-11214, 1996). Starch sample $(5 \mathrm{~g})$ was stirred in $0.1 \mathrm{M} \mathrm{HCl}$ for $30 \mathrm{~min}$. The slurry was then filtered and washed with distilled water until free of chloride ions. The filtered cake was transferred to $300 \mathrm{ml}$ water and the starch slurry was heated in a boiling water bath with continuous stirring until gelatinized and continue stirring at that temperature for another $15 \mathrm{~min}$. The hot sample was titrated with $0.1 \mathrm{M} \mathrm{NaOH}$ using phenolphthalein as an indicator.

\subsection{Determination of solubility and swelling power}

The water solubility and swelling power analyses were evaluated by the method describe by Kusumayanti (2015) with slight of modification, respectively [25]. These were carried out by weighing $0.1 \mathrm{~g}$ of modified cassava starch and $10 \mathrm{ml}$ of distilled water into a reaction tube. The tube was placed it on beaker bath and heated at $60{ }^{\circ} \mathrm{C}$ for 30 minutes. After heating process, the sample was centrifuged (C-5 Test Tube Centrifuge) at $1600 \mathrm{rpm}$ for $15 \mathrm{~min}$. The supernatant was removed from sediment carefully. The swelling power was determined as sediment weight per initial dry weight of sample. $5 \mathrm{ml}$ of supernatant was collected and dried it into a constant weight. The water solubility was expressed as weight percent of the soluble flour of the heated solution.

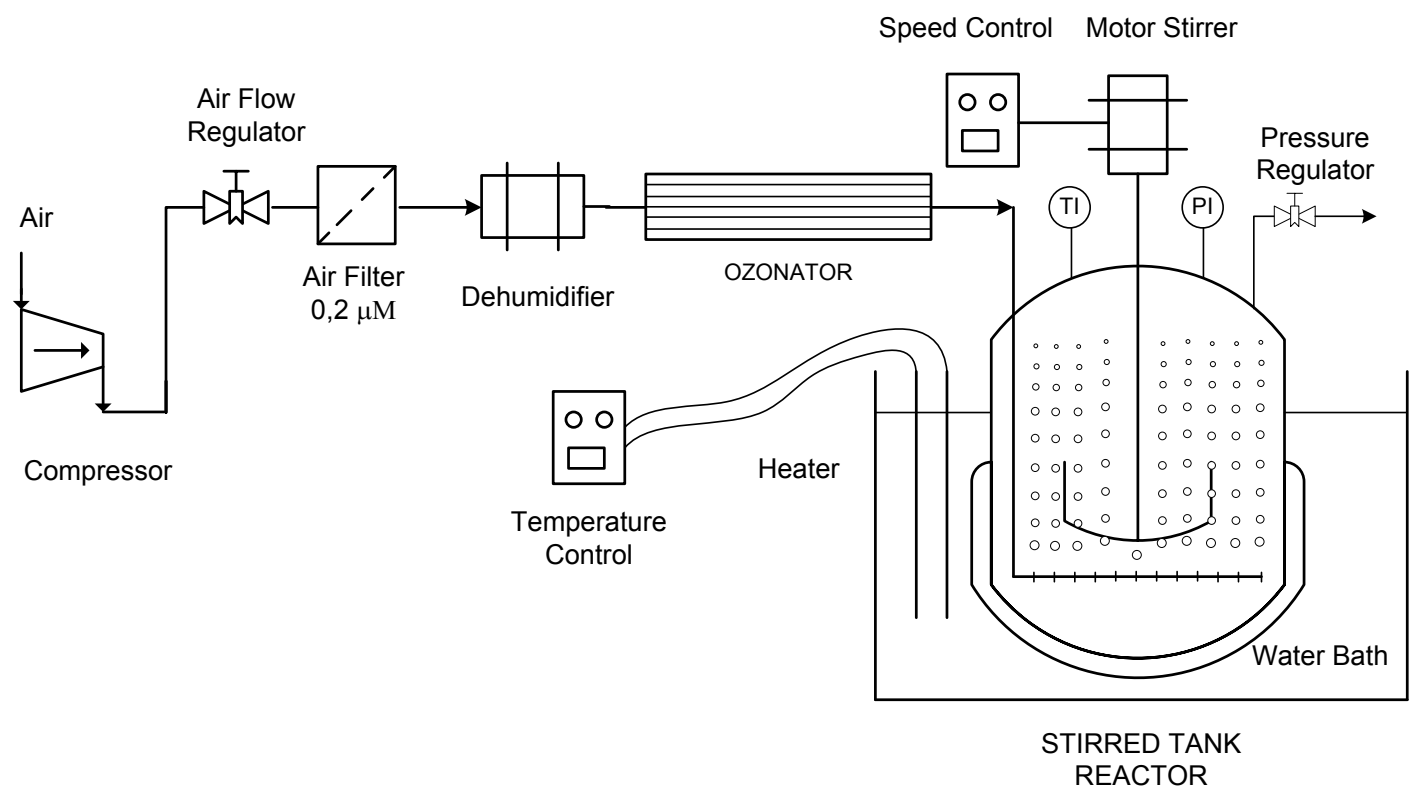

Fig. 3 Experiment apparatus of ozonisation in the stirred tank reactor 


\section{Results and Discussions}

\subsection{The effect of $\mathrm{pH}$ on carboxyl content (\%)}

Various pH (7-10) were applied on starch modification using ionization to investigate the carboxyl content $(\%)$ of cassava starch. Figure 2 shows the effect of $\mathrm{pH}$ on carboxyl group during ozone reaction time $(0-$ 240 minutes). The carboxyl content of ozone-modified cassava starch was determined by the ISO method (ISO11214, 1996) using phenolphthalein as acid-alkaline indicator.

Generally, carboxyl content increased in the first 120 minutes ozone reaction, but it was not significant different in the last 120 minutes. Both oxidized starches had higher carboxyl contents in comparison with unmodified starch. The highest value of carboxyl group $(0.092 \%)$ was obtained at $\mathrm{pH} 10$ for 120 minutes ozone reaction time. Some factors might influence the complex reaction mechanism of ozone modification, such as type of starch, oxidizing agent, and reaction condition. Modification starch using ozone allows hydroxyl groups replaced by carboxyl and carbonyl groups [26]. The carboxyl and carbonyl content indicates the level of oxidation. According in Figure 2, the higher level of carboxyl content was obtained at alkaline $\mathrm{pH}$.

\subsection{The effect of pH on swelling power $(\%)$}

The effect of $\mathrm{pH}$ on oxidation modification was conducted on cassava starch. Figure 3 depicts the influence of $\mathrm{pH}$ (7-10) on swelling power of modified starch. Swelling power signify the water storing capacity of starch, which is generally used as one of parameters in food application, especially in baking process.

Modified starch which was produced by ozone reaction at $\mathrm{pH} 10$ had a highest carboxyl level but lowest of swelling power in comparison with others $\mathrm{pH}$ reaction. The significant decreases of swelling power

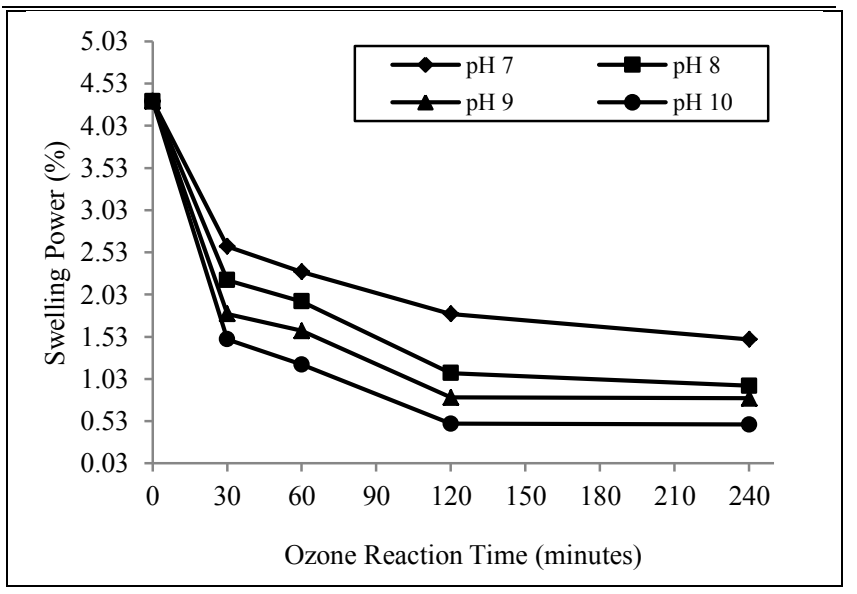

Fig 3. Swelling power of ozone modified cassava starch were obtained up to $65 \%$ and $81 \%$ in the first 30 and 120 minutes of ozone reaction, respectively. This characteristic is influenced by the amylase and amylopectin level. Oxidation reaction could increase the amylose content due to the high of carboxyl group. For this reason, the swelling ability of modified starch decreased, and it might be a disadvantageous for baking process (Figure 3).

\subsection{The effect of $\mathrm{pH}$ on water solubility (\%)}

Figure 4 represents the effect of $\mathrm{pH}$ on modified starch's water solubility. Commonly, the values of water solubility are in contrast with swelling power. The value of this parameter increased along with ozone reaction time. This result is in agreement with carboxyl content (Figure 2). The highest value of water solubility was achieved at $\mathrm{pH} 10$. This trend was also similar with Kusumayanti (2015) [25]. The graphic pattern of water solubility was in contrast with swelling power. However, there is no straight relation between water solubility and swelling power that could be investigated [27].

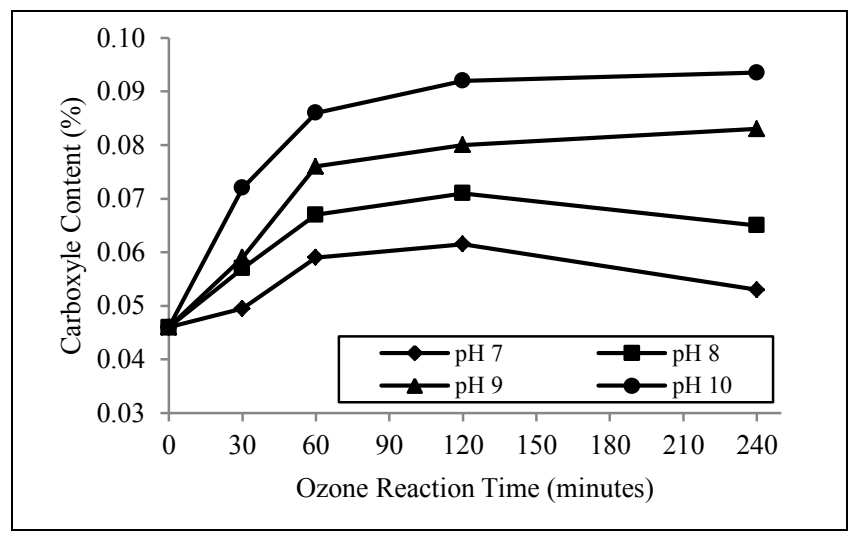

Fig. 2 Carboxyl content of ozone modified cassava starch.

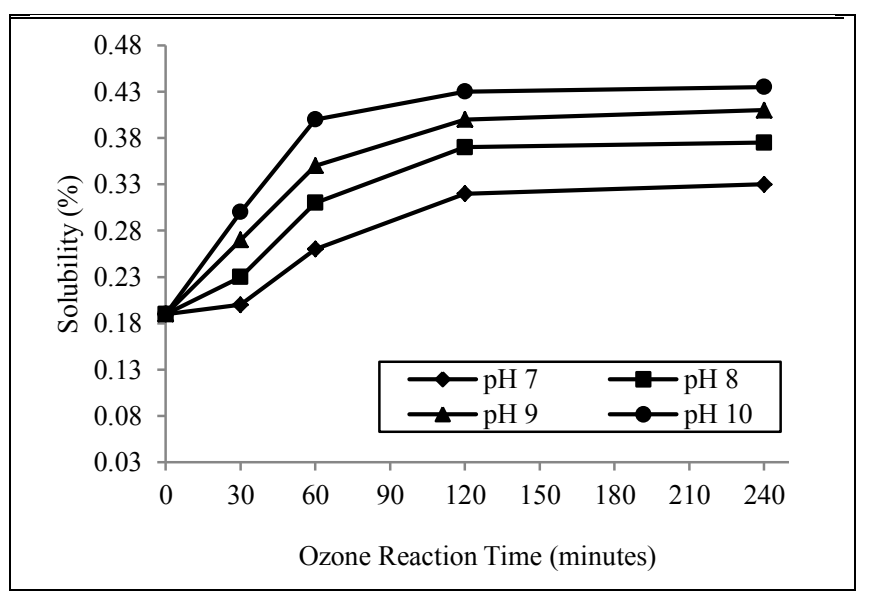

Fig 4. Water solubility of ozone modified cassava starch 


\section{Conclusions}

Modification of cassava starch was conducted using ozone oxidation. Water solubility of oxidized cassava starch increases along with reaction time. Reaction condition at $\mathrm{pH} 10$ provided the higher value of carboxyl content and water solubility, but the lower of swelling power. This increase in solubility indicates that the modified oxidation starch readily dissolves in water, due to its small size granules and high amylose content.

\section{Acknowledgement}

Authors thank to Diponegoro University through Fundamental Research Grant Program for funding this research.

\section{References}

1. J. J. M. S. Jane., J. Macromol. Sci., Pure Appl. Chem., 32, 4 (1995)

2. J. M. N. Miller., Starch/Stärke, 49, 4 (1997)

3. R. N. Tharanathan., Critical Reviews in Food Science and Nutrition, 45, 371-384. (2005)

4. S. Sumardiono, I. Pudjihastuti, M. Taufani, F. Yahya, AIP Conf. Proc., 1840, 060005 (2017)

5. S. Sumardiono, I. Pudjihastuti, Budiyono, H. Hartanto, I. C. Sophiana, AIP Conf. Proc., 1840, 060006 (2017)

6. S. Sumardiono, M. Djaeni, B. Jos, I. Pudjihastuti, M. Abdallatif, Adv. Sci. Lett., 23 (2017)

7. S. Sumardiono, R. B. Rakhmawati, Adv. Sci. Lett., 23, 6 (2017)

8. P. Parovuori., A. Hamunen., P. Forssell., K. Autio., K. Poutanen., Starch/Stärke, 47, 1 (1995)

9. F. Kantouch., S. Tawfik., Starch/Stärke, 50 (1998)
10. D. Kuakpetoon., Y. J. Wang., Starch/Stärke, 53 (2001)

11.E. Bidzinska., K. Dyrek., T. Fortuna, M. Labanowska., S. Pietrzyk., Starch/Stärke, 56 (2004)

12. C. E. C. Murillo., Y. J. Wang., L. A. B. Perez, Starch/Stärke, 60 (2008)

13. K. Sangseethong., S. Lertphanich., K. Sriroth., Starch/Stärke, 61(2009)

14. P. Muhrbeck., A. C. Eliasson., A. C. Salomonsson., Starch/Stärke, 4, 11 (1990)

15. A. Hebeish., F. El-Sisy., S. A. Abdel-Hafiz., A. A. Abdel-Rahman., M. H. El-Rafie., Starch/Stärke, 44, 10 (1992)

16. A. N. Jyothi., K. Sasikiran., M. S. Sajeev., R.Revamma., S. N. Moorthy., Starch/Stärke, 57, 11 (2005)

17. S. Veelaert., M. Polling., D. de Wit., Starch/Stärke, 47, 7 (1995)

18. P. Tolvanen, A. Sorokin, P. Mäki-Arvela, S. Leveneur, D. Y. Murzin, T. Salmi, Ind. Eng. Chem. Res., 50, 2 (2010)

19. K. Sangseethong, N. Termvejsayanon, K. Sriroth,. Carbohydr. Polym., 82, 2 (2010)

20. O. S. Lawal, K. O. Adebowale, B. M. Ogunsanwo, L. L. Barba, N. S. Ilo, Int. J. Biol. Macromol., 35, 1-2 (2005)

21. S. Veelaert, D. de Wit, K. F. Gotlieb, R. Verhé,. Carbohydr. Polym., 33, 2-3 (1997)

22. A. Bohme., Ozone: Sci. Eng., 21 (1999)

23. V. Camel., A. Bermond., Water Res., 32 (1998)

24. U. von Gunten., C. J. Hoign., Environ. Sci. Technol., 28 (1994)

25. H. Kusumayanti, N. A. Handayani, H. Santosa, Procedia Environ. Sci., 23 (2015)

26. A. R. G. Dias, E. da Rosa Zavareze, E. Helbig, F. A. de Moura, C. G. Vargas, C. F. Ciacco, Carbohydr. Polym., 86, 1 (2011)

27. A. C. Kumoro, D. S. Retnowati, C. S. Budiyati,. Research Journal of Applied Sciences, Engineering and Technology, 4, 1 (2012) 